\title{
Investigating Fatigue Life Effects on the Vibration Properties in Friction Stir Spot Welding Using Experimental and Finite Element Modal Analysis
}

\author{
Nima Jafarzadeh Aghdam* - Soran Hassanifard - Mir Mohammad Ettefagh - Arvin Nanvayesavojblaghi \\ University of Tabriz, Mechanical Engineering Department, Iran
}

Frequency response and vibration study of friction-welded specimens with different fatigue life properties is very important. Friction stir spot welding (FSSW) is one of the welding methods applied in different types of manufacturing processes such as in the vehicle and aerospace industries. Therefore the main purpose of this paper is better understanding of the correlation between natural frequencies and fatigue crack initiation of the FSSW in four different welding processes. For this purpose fatigue and experiment modal analysis tests were carried out at different fatigue strength levels. The experimental modal analysis was carried out on four different types of friction stir spot welded specimens after different fatigue life tests. Finite element (FE) modelling was performed in ABAQUS software using the Lanczos method for comparing the obtained results with the experimental tests. Some important findings were determined from the experimental and FE modelling results. One of the interesting findings was similar behaviour between the FE model and the experimental test for defined frequency ranges.

Keywords: friction spot welding, fatigue damage, frequency response, experimental modal analysis, finite element modelling, vibration characteristics

\section{O INTRODUCTION}

Joining metal sheets by welding different materials is absolutely necessary in the automotive and other industries. However, different welding methods may be used depending on the applications and materials. Spot welding is one of the applicable methods, which includes resistance spot welding (RSW) and friction stir spot welding (FSSW). Each method has its individual characteristics and advantages or disadvantages. RSW is one of the most popular welding methods, but in joining light-metals such as aluminium alloys, the application of this method would lead to some major difficulties [1]. Recently, automotive, aerospace and other industries have begun to pay serious attention to the FSSW method for joining metal sheets [2] to [3]. This method could be considered as an upgraded variant of the friction stir welding (FSW) process. Both FSW and FSSW processes can be termed as standard methods of welding aluminium alloys. FSW is a solid-state joining process which means that the metal is not fully melted and instead it is just softened [4]. One of the most important features of the FSW process is that the main characteristics of the materials remain unchanged as much as possible. In order to apply the FSSW method correctly, it is necessary to provide a proper model, which would allow for a more exact study of the fatigue and dynamic properties of the welding. There are some studies that deal with modelling and prediction of fatigue life of metals welded by FSSW methods in various applications. Some of these studies will be described below.

The fatigue life of FSSW in aluminium 6061-T6 sheets were investigated by Wang and Chen [5]. In this work, tool geometry, the rotational speed, the holding time and the downward force were considered the most important processing parameters. They modelled the three dimensional FSSW's crack as a twodimensional crack problem. The fatigue life for FSSW has also been investigated by Lin et al. [6] to [8] and by Ericsson et al. [9]. They used fracture mechanics to solve the modelling problem. In all of the abovementioned papers the weld nugget is modelled as a cone. For example, in [6] to [8], a fatigue crack growth model was adopted based on the Paris law and the local equivalent stress intensity factors. Kinked cracks were applied to predict the fatigue life of FSSW and the fatigue crack propagation; the modelling results were then compared with experimental ones. In [9] the global stress intensity factor was used to predict the crack growth rate of the FSSW. These stress intensity factors were calculated from FE models. The main purpose of the above-mentioned works was to predict fatigue life using proper modelling, but additional goal of other studies has been to model welding in order to study the dynamic and vibrational characteristics of the model, which are very important for designing proper welding techniques, especially in the automotive and aerospace industries. Shang [10], Wang et al. [11] and Shang et al. [12] and [13] investigated the effects of fatigue cracks on the frequency responses of RSW joints and concluded that the natural frequencies of the 
Table 1. Chemical properties of aluminium 7075-T6 (Maximum values if range not presented)

a) Chemical composition of aluminium $7075-\mathrm{T} 6$ [\% weight]

\begin{tabular}{|c|c|c|c|c|c|c|c|c|c|c|}
\hline $\mathrm{Si}$ & $\mathrm{Fe}$ & $\mathrm{Cu}$ & $\mathrm{Mn}$ & $\mathrm{Mg}$ & $\mathrm{Cr}$ & $\mathrm{Zn}$ & $\mathrm{Ti}$ & Others, each & Others, total & $\mathrm{Al}$ \\
\hline 0.4 & 0.5 & 1.2 to 2 & 0.3 & 2.1 to 2.9 & 0.18 to 0.28 & 5.1 to 6.1 & 0.2 & 0.5 & 0.15 & Balance \\
\hline
\end{tabular}

b) Mechanical properties of aluminium 7075-T6

\begin{tabular}{ccccc}
\hline Density $\times 1000\left[\mathrm{~kg} / \mathrm{m}^{3}\right]$ & Elastic modulus [GPa] & Ultimate tensile strength [MPa] & Yield strength [MPa] & Elongation [\%] \\
\hline 2.81 & 71 & 578 & 469 & 33 \\
\hline
\end{tabular}

Table 2. Main parameters of the four types of FSSW

\begin{tabular}{lcccc}
\hline & $\begin{array}{c}\text { Penetration depth of the } \\
\text { shoulder }[\mathrm{mm}]\end{array}$ & $\begin{array}{c}\text { Rotational speed of the } \\
\text { rotating tool }[\mathrm{rpm}]\end{array}$ & $\begin{array}{c}\text { Vertical pin advance } \\
\text { speed [mm/min] }\end{array}$ & $\begin{array}{c}\text { Force duration or } \\
\text { holding time [ms] }\end{array}$ \\
\hline Type1 & 1.3 & 2500 & 8 & 5 to 6 \\
\hline Type2 & 1.3 & 1600 & 8 & 5 to 6 \\
\hline Type3 & 0.9 & 2000 & 8 & 5 to 6 \\
\hline Type4 & 1.3 & 2000 & 8 & 5 to 6 \\
\hline
\end{tabular}

welds change a lot when the specimens are put under cyclic loading based on counting the cycles or stress reversals until destruction. Wang and Barky [14] and [15] also studied fatigue cracks and their effects on the specifications of dynamic responses of RSW joints and used their results to detect and diagnose fatigue cracks.

In this paper, fatigue and experiment modal analysis test were used to come to a better understanding of the correlation between the natural frequencies and fatigue crack initiation of the FSSW in four different welding processes. For this purpose, four types of specimens, each of them using different FSSW process to weld two aluminium 7075-T6 sheets together, were used and were then exposed to cyclic loading to generate different levels of fatigue. At each level, the welded sheets were tested by experimental modal analysis method in order to extract the natural frequencies of the FSSW specimens in each of the four types. An FE model of the four types of FSSW specimens were provided in ABAQUS and the natural frequencies of the FE model were extracted at different fatigue levels, which were modelled as a proper crack. Finally the obtained results in the experimental and modelling sections of this work will be illustrated and discussed.

\section{FRICTION STIR SPOT WELDING SETUP AND PROCESSING}

In this investigation, distinct Aluminium 7075T6 sheets were welded using four different FSSW process parameters. The chemical composition of the aluminium 7075-T6 sheet is presented in Table 1a and the mechanical properties of the sheets are presented in Table $1 b$.
To start the welding process, two sheets of aluminium 7075-T6 are joined in a lap configuration as shown in Fig. 1. The lower sheet is put on a supporting plate while a rotating tool, as shown in Fig. 2 , presses the upper sheet. The back plate supports the downward force of the rotating pin while the rotational speed of the pin results in softening the aluminium but not melting it. The downward force of the pin causes penetration of the pin into the softened material. By the time the shoulder of the tool reaches the surface of the upper sheet, more heat is generated due to a larger contact surface and additional friction between the tool shoulder and the aluminium sheet, which causes a larger region of the material to be softened. So the softened regions of the sheets are pressed and at the same time stirred, which leads to a metallurgical bond around the rotating pin. At the end of the welding process, the tool was retracted and a characteristic hole in the middle of the weld was left. The main parameters of the welding process for different sets of welded joints are summarized and presented in Table 2. Hereafter, these four different sets of friction stir spot welded joints will be called Type1, Type2, Type3 and Type4, respectively. The experimental fatigue test setup, provided in the fatigue test laboratory, is illustrated in Fig. 3. Using this setup the fatigue test was carried out to generate different types of fatigue life.

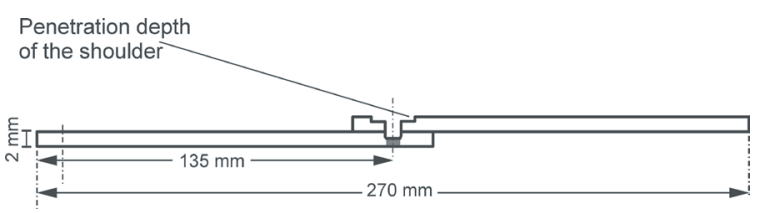

Fig. 1. The two sheets of aluminium 7075-T6, joined by FSSW 


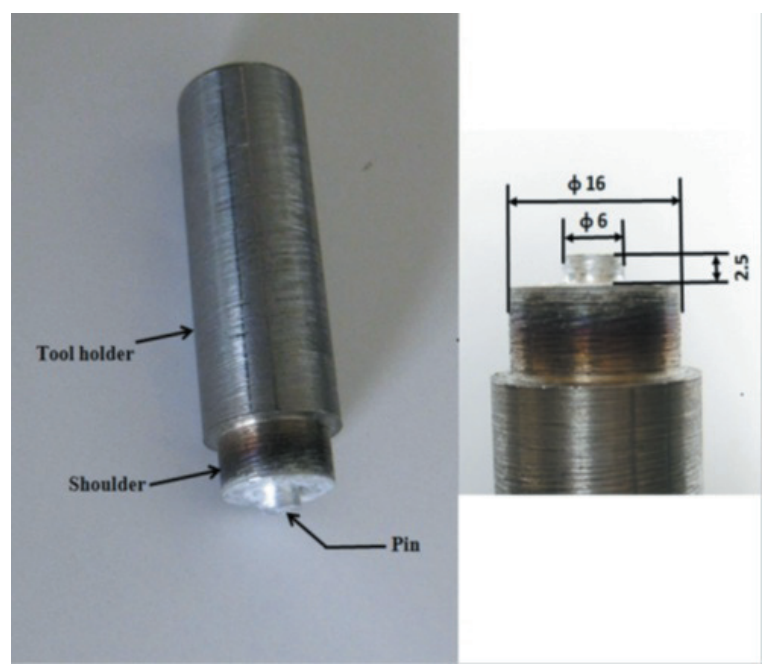

Fig. 2. The rotating tool

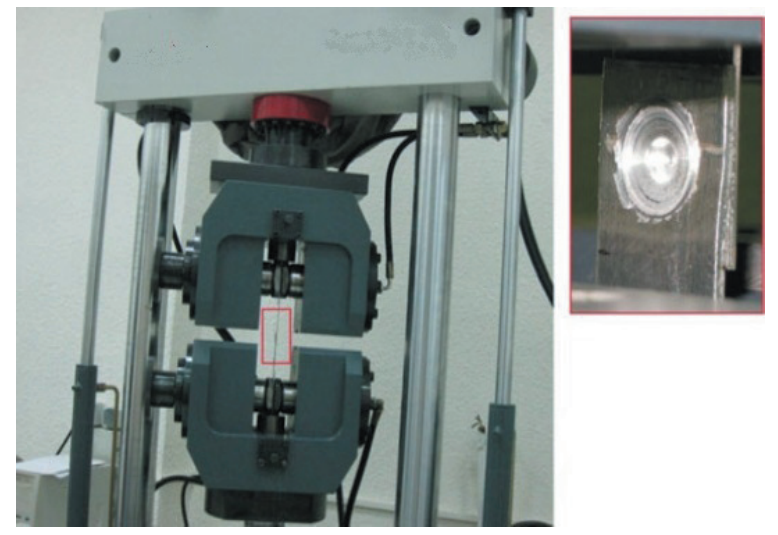

Fig. 3. The experimental fatigue test setup

\section{FRICTION STIR SPOT WELDS (FSSW) FINITE ELEMENT MODELING}

Three-dimensional FE analysis was used to determine the relationship between the length of fatigue cracks and the frequency response characteristics (natural frequencies and mode shapes). The severity of the fatigue damage can be modelled using the fatigue crack length or depth [12]. In this study, the finite element mesh contained approximately 34000 elements with a maximum element length of $3 \mathrm{~mm}$. The element type was 10-node quadratic tetrahedron (Fig. 4). To simulate the experimental conditions, clamped-free condition were applied. The mechanical properties, considered for the FSSW specimens were a density of $2810 \mathrm{~kg} / \mathrm{m}^{3}$, a Young's modulus of $71 \mathrm{GPa}$, and a Poisson's ratio of 0.33 . In this paper, the steps of fatigue crack growth modelling are as follows: The crack was modelled in the form of an elliptical surface and it is first initiated near tip of the circumferential notch around the nugget as shown in Figs. 5 and 6. It then grows perpendicular to the applied load and finally the crack reaches through the thickness of the plate in the direction of the specimen width [12] to [13]. It should be added that the fatigue cracks are assumed to initiate at a distances of $1 \mathrm{~mm}$ from the nugget edge. The site of the simulated crack initiation in the 3D FE model is shown in Fig. 6 by a cut-away view of the FE model as illustrated in Fig. 5.

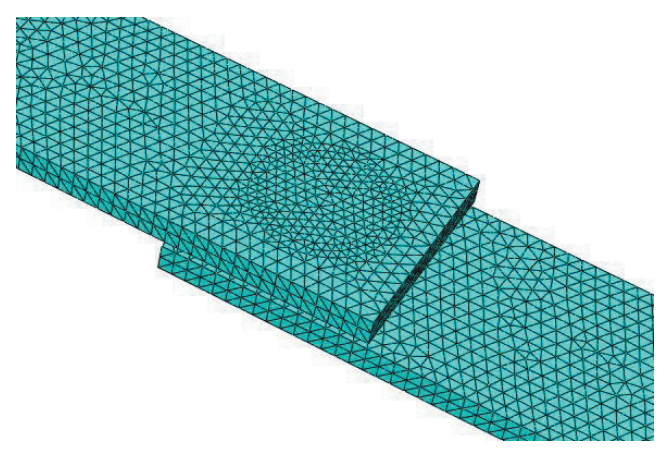

Fig. 4. FE mesh and simulation of FSSW specimen

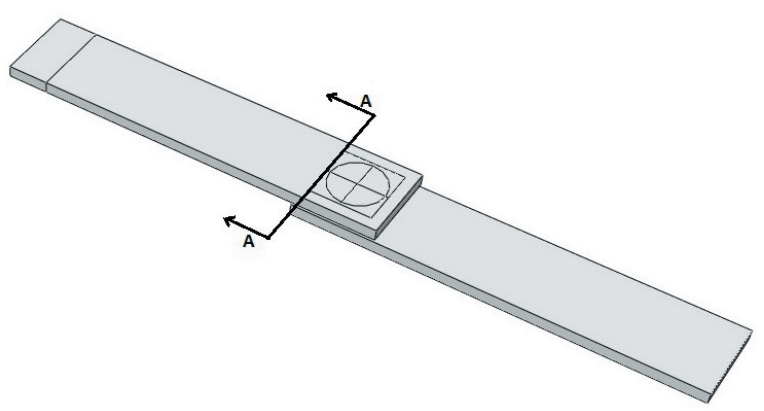

Fig. 5. FE model of the fatigue crack
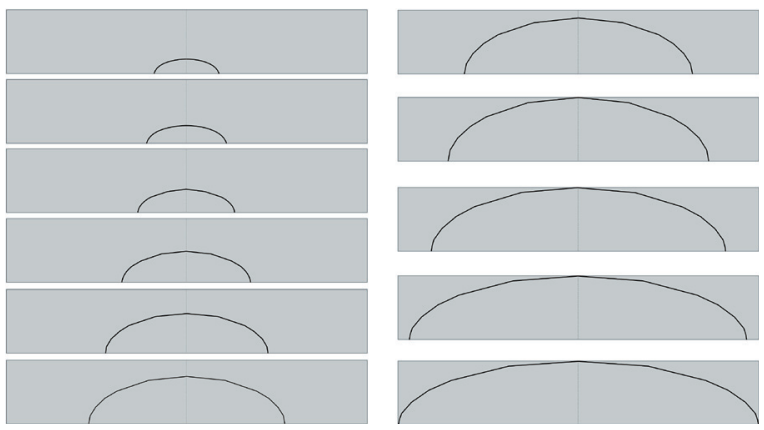

Fig. 6. Fatigue crack growth steps in the model

It should be noted that according to the aforementioned experimental observations, the shape of the propagating surface cracks in a plate is approximately semi-elliptical. Therefore, the models built in this study assumed that the growing crack 
was of a semi-elliptical shape [12] that maintained a constant aspect ratio (the ratio between the surface crack length and the crack depth) until the surface crack extended through the thickness of plate [13]. The aspect ratios were taken as 0.5 . The steps of the fatigue crack development process that were assumed from initiation to propagation are shown in the $\mathrm{FE}$ model in Fig. 6. A microscopic image of a fatigue crack in one of the FSSW types is shown in Fig. 7.

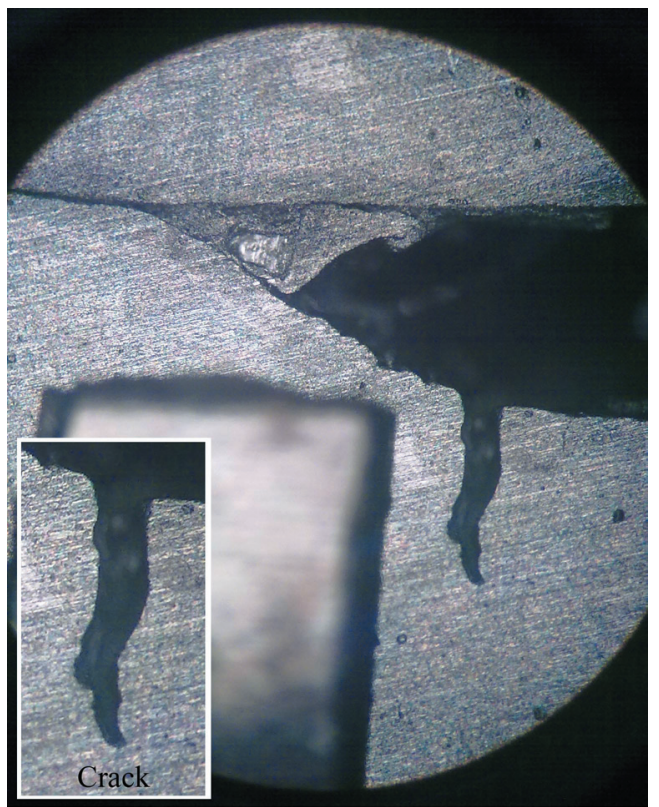

Fig. 7. Cross-section of a frictional stir spot weld after creation of a fatigue crack under cyclic loadings

\section{EXPERIMENTAL FATIGUE TESTS}

Fatigue tests of four different types of FSSW specimens were conducted at different load levels ranging from 1.5 to $5 \mathrm{kN}$ using a load controlling technique at a frequency of $10 \mathrm{~Hz}$ and a load ratio of 0.1 by applying a $250 \mathrm{kN}$ Zwick/Amsler fatigue testing machine. Fatigue test results of the four FSSW types are shown in Fig. 8.

As it can be seen in Fig. 8, the fatigue life of the specimens is reduced with decreasing the tool rotational speed, especially in a low cycle fatigue regime. Increasing the tool penetration depth from 0.9 to $1.3 \mathrm{~mm}$ has no major impact on increasing the fatigue life. Although the four types of FSSW specimens have the same total fatigue lifetime in a high cycle fatigue regime, they may have a different crack initiation and propagation life. Therefore, modal analysis should be used primarily for assessing the fatigue crack initiation of the four FSSW type's specimens and, for this reason, all the specimens are loaded into an HCF regime before the modal analysis test.

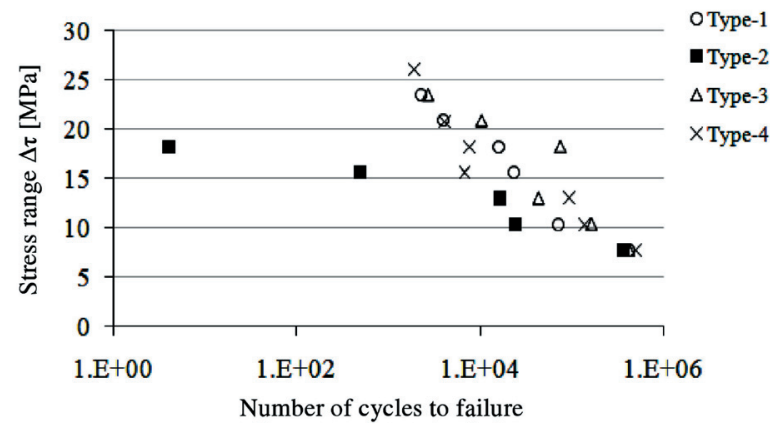

Fig. 8. Fatigue test results of friction stir spot welded specimens; $\Delta T=\Delta P /\left(\right.$ nugget area), and (nugget area) $=\pi\left(r_{0}^{2}-r_{i}{ }^{2}\right)$ where $r_{0}$ is shoulder radius and $r_{i}$ is pin radius

\section{EXPERIMENTAL MODAL ANALYSIS TESTS}

In order to identify the natural and mode shape of the four different FSSW types, experimental modal analysis [16] was implemented as shown in Fig. 8. Every FSSW types was excited by a shaker (type 4809 $\mathrm{B} \& \mathrm{~K})$ at the free end by applying white Gaussian noise in the frequency range of $10 \mathrm{kHz}$.

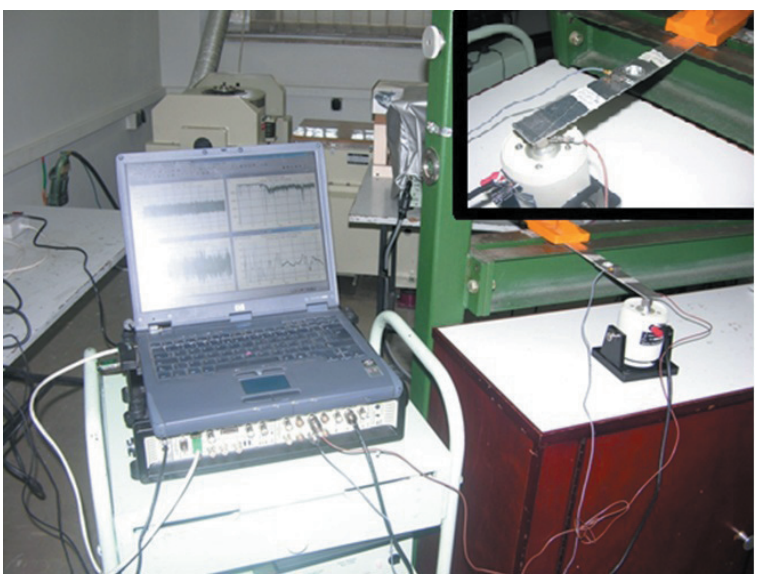

Fig. 9. Experimental modal analysis set-up

The dynamic response is measured by a piezoelectric acceleration sensor (type $4507 \mathrm{~B} \& \mathrm{~K}$ ) attached to the middle of the specimen. The analogue data gathered from each sensor was processed using a Pulse system [17] and converted to digital data and saved in a personal computer. The frequency response function (FRF) was then extracted and analysed by MeScope software [18] using the polynomial modal analysis method to find out the natural frequencies of the 
specimens. The above mentioned modal analysis test was applied to the specimen after applying the fatigue test with different fatigue lives. In order to validate the modal analysis test, the FRF and corresponding coherence of one of the FSSW types is shown in Fig. 10 as an example.

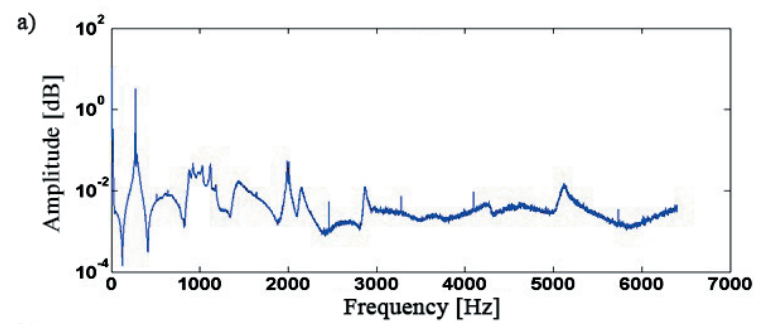

b)

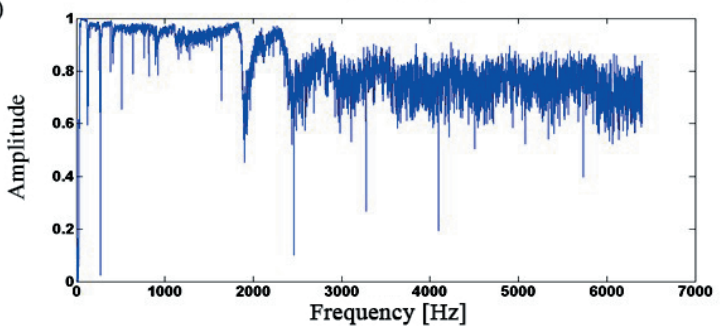

Fig. 10. The a) FRF and b) corresponding coherence of Type1

\section{RESULTS AND DISCUSSION}

As described in previous sections, four different FSSW types were provided for experimental fatigue and modal analysis testing. Figs. 11 to 14 present experimental modal analysis test results for every FSSW type by depicting the percentage of frequency reduction versus the percentage of fatigue damage. It should be noted that to obtain the values of the fatigue damage percentage, the fatigue test of the specimens were terminated at some specific fatigue life value, which was smaller than the total fatigue life. Therefore the fatigue damage percentage is calculated in percent by dividing the terminated life by the total life. As shown in these figures, the major trend noted is a lowering of all the $1^{\text {st }}$ to $5^{\text {th }}$ natural frequencies as the fatigue crack grows in each of the types. However, the first natural frequency's decrease is more visible than that of the other frequencies. Some disorders are seen in the overall process of frequency lowering while fatigue damage increases which is a result of a possible variation in the specimens' dimensions due to the fatigue test. For example, a small length increase during modal analysis test may cause the frequency to increase. This is normal in experimental tests, because noise, especially measurement noises, can have very serious effects on modal analysis tests. As another example, it is not possible to provide the boundary condition as an ideal cantilever beam and preserve this condition in different tests of the specimens when opening and closing them on a fixture during modal analysis. In addition, positioning the measurement sensors and exciting shaker in exactly the same position for different tests of the specimens is another reason for having some errors in extracting the natural frequencies. Another issue that contributes to errors is the length positioning of the specimens when installing them in the cantilever fixture for the modal analysis test, which strongly contributes to change the natural frequencies.

The results of the numerical modal analysis of the FE model, introduced in Section 3 of this paper, are presented in Fig. 15. In this figure, the percentage of frequency reduction versus fatigue crack length is illustrated. In order to better illustrate this, the FEM and experimental results have been depicted in one figure after normalization of the percent of fatigue damage and frequency reduction, which correspond to the horizontal and vertical axis, respectively (Fig. 16).

By considering the above-mentioned figures, it maybe deduced that firstly, the same decreasing behaviour in the natural frequencies seen in the experimental results is obvious for different frequency domains. Secondly, despite increases in the frequency domain, frequency reduction is not reduced and this phenomenon is also obvious in the experimental results. In other words, fatigue/crack damage effects on frequency reduction are not directly related to the frequency domain (frequency band). Although at some frequencies, the reduction may be more than at other frequencies. For example, in Fig. 15, the frequency reduction in the $2^{\text {nd }}$ frequency (a low band frequency) is more than in other frequencies. As another example, a frequency reduction in the $4^{\text {th }}$ frequency (a high band frequency) is less than other frequencies. This kind of trend can be found in the experimental results as well. For example, considering Figs. 10 to 13, the frequency reduction in the 1st frequency is more than the other frequencies. As another example, Figures 11 to 14 show that frequency reduction in the $5^{\text {th }}$ frequency is less than in other frequencies in the above-mentioned experimental results. The reason for the different frequency numbers and presence of a frequency reduction when comparing both experimental and numerical results may be due to the fact that that the FE modelling frequency domain is different compared to the corresponding domain in the experimental test due to some unknown modelling errors. This error may be minimized by a more exact selection of the mechanical property such as module 
of elasticity in the FE model. This task may be carried out by FE model updating in future.

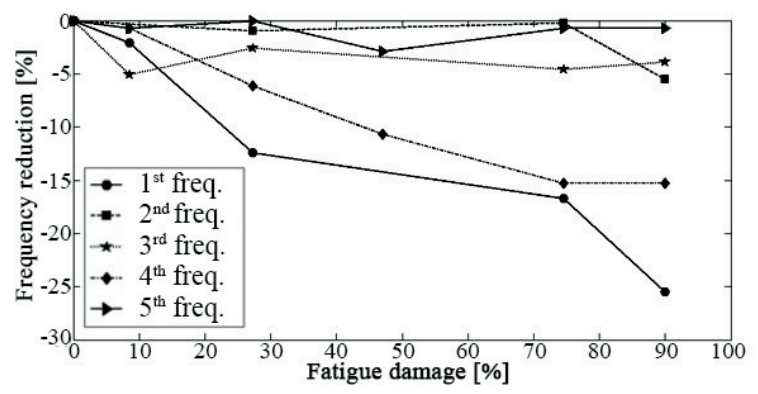

Fig. 11. Results of the experimental modal analysis test on the Type1 FSSW by illustrating the percentage of frequency reduction against fatigue damage percent

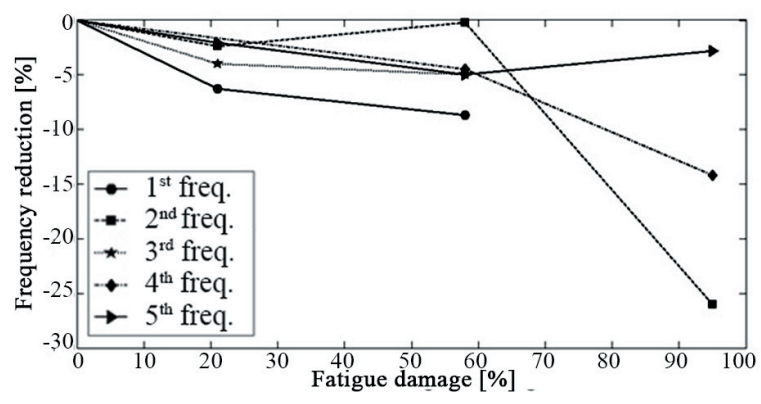

Fig. 12. Results of the experimental modal analysis test on Type2 FSSW by illustrating percentage of frequency reduction against fatigue damage percent

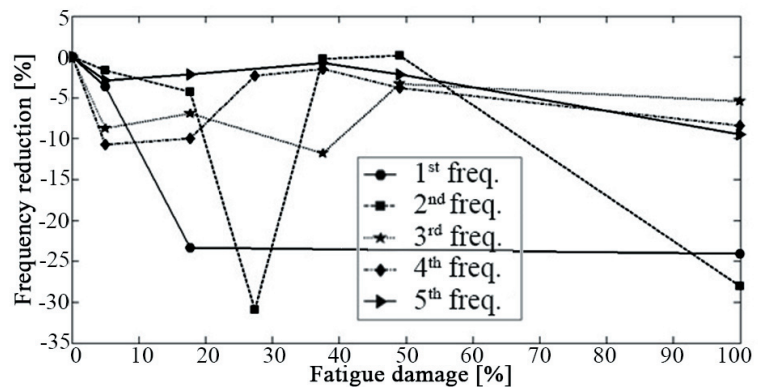

Fig. 13. Results of experimental modal analysis test on Type3 FSSW by illustrating percentage of frequency reduction against fatigue damage percent

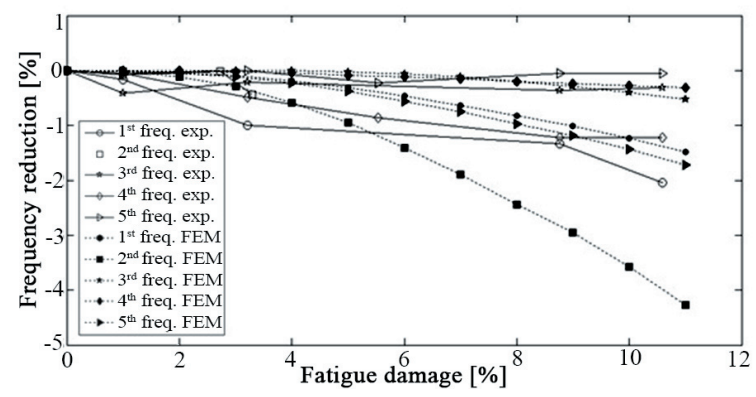

Fig. 14. Results of experimental modal analysis test on Type4 FSSW by illustrating percentage of frequency reduction against fatigue damage percent

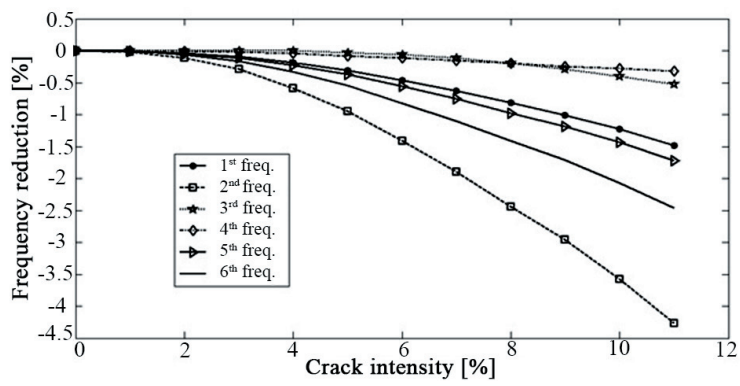

Fig. 15. Results of numerical modal analysis of the FE model

\section{CONCLUSIONS}

In this paper experimental and numerical modal analysis test was designed to study and analyze the effects of fatigue damage on frequency response function (vibration characteristics) of the four types of FSSW with different welding processes. The experimental modal analyses were carried out on four types of FSSW after different fatigue life tests. FE modelling was also carried out in ABAQUS and by using the Lancsoz method the obtained results were compared with experimental test. One of the important findings of this research is that the fatigue damage effect on the frequency response function of the four types of FSSW has no direct relationship with the frequency domain level. In other words it was shown in experimental tests' results that at some low frequency domains, the fatigue damage effect is more than the high frequency domain and result were also validated by FE model results. Therefore, as the frequency domain increases, the fatigue effect may decrease under some conditions or asthe frequency domain decreases the fatigue effect may increases. Another important finding is that for each individual frequency band with increasing fatigue damage level, the frequency reduction is obvious in the experimental test except in a few cases and this result is also illustrated in the FE model results.

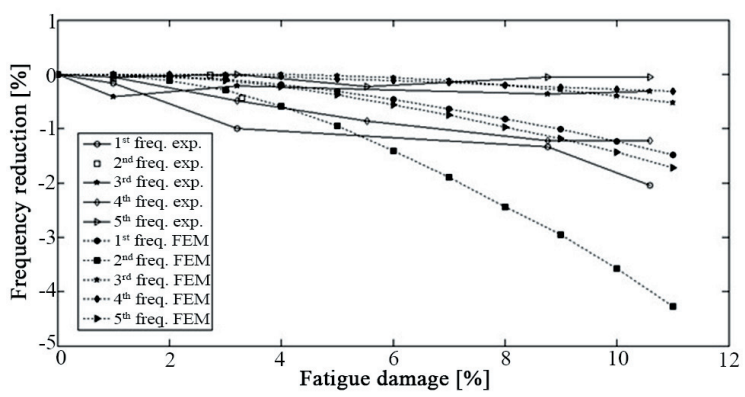

Fig. 16. Comparing the numerical modal analysis of the FE model and the experimental test (Type1 FSSW) 


\section{REFERENCES}

[1] Spinella, D.J., Brockenbrough, J.R., Fridy, J.M. (2005). Trends in aluminium resistance spot welding for the auto industry. Welding Journal, vol. 84, p. 34-40.

[2] Baek, S.W., Choi, D.H., Lee, C.Y., Ahn, B.W., Yeon, Y.M., Song, K., Jung, S.B. (2010). Microstructure and mechanical properties of friction stir spot welded galvanized steel. Materials Transactions, vol. 51, no. 5, p. 1044-1050, DOI:10.2320/matertrans.M2009337.

[3] Hancock, R. (2004). Friction welding of Aluminum cuts energy cost by $99 \%$. Welding Journal, vol. 83 , no. 2, p. 40.

[4] Bilici, M.K. (2012). Effect of tool geometry on friction stir spot welding of polypropylene sheets. Express Polymer Letters, vol. 6, no. 10, p. 805-813, DOI:10.3144/expresspolymlett.2012.86.

[5] Wang, D.A., Chen, C.H. (2009). Fatigue lives of friction stir spot welds in aluminum 6061-T6 sheets. Journal of Materials Processing Technology, vol. 209, no. 1, p. 367-375, DOI:10.1016/j.jmatprotec.2008.02.008.

[6] Lin, P.C., Pan, J., Pan, T. (2005). Investigation of fatigue lives of spot friction welds in lap-shear specimens of aluminum 6111-T4 sheets based on fracture mechanics. SAE Technical Paper, no. 2005-01-1250.

[7] Lin, P.C., Pan, J., Pan, T.(2006). Fatigue failures of spot friction welds in aluminum 6111-T4 sheets under cyclic loading conditions. SAE Technical Paper, no. 2006-011207.

[8] Lin, S.H., Pan, J., Wung, P., Chiang, J. (2006). A fatigue crack growth model for spot welds under cyclic loading conditions. International Journal of Fatigue, vol. 28, no. 7, p. 792-803, DOI:10.1016/j.ijfatigue.2005.08.003.

[9] Ericsson, M., Jin, L.Z., Sandström, R. (2007). Fatigue properties of friction stir overlap welds. International Journal of Fatigue, vol. 29, no. 1, p. 57-68, DOI:10.1016/j.ijfatigue.2006.02.052.
[10] Shang, D.G. (2009). Measurement of fatigue damage based on the natural frequency for spot-welded joints. Materials and Design, vol. 30, no. 4, p. 1008-1013, DOI:10.1016/j.matdes.2008.06.048.

[11] Wang, R.J., Shang, D.G., Li, L.S., Li, C.S. (2008). Fatigue damage model based on the natural frequency changes for spot-welded joints. International Journal of Fatigue, vol. 30, no. 6, p. 1047-1055, DOI:10.1016/j. ijfatigue.2007.08.008.

[12] Shang, D.G., Barkey, M.E., Wang, Y., Lim, T.C. (2003). Fatigue damage and dynamic natural frequency response of spot-welded joints. SAE Technical Paper, no. 2006-01-0695.

[13] Shang, D.G., Barkey, M.E. (2006). Analysis of fatigue crack behavior based on dynamic response simulations and experiments for tensile-shear spot-welded joints. Fatigue \& Fracture of Engineering Materials \& Structures, vol. 29, no. 1, p. 23-30, DOI:10.1111/ j.1460-2695.2006.00955.x.

[14] Wang, G., Barkey, M.E. (2005). Fatigue crack identification in tensile-shear spot welded joints by dynamic response characteristics. Transactions of the ASME, vol. 127, no. 3, p. 310-317, DOI:10.1115/1.1925286.

[15] Wang, G., Barkey, M.E. (2004). Fatigue cracking and its influence on dynamic response characteristics of spot welded specimens. Experimental Mechanics, vol. 44, no. 5, p. 512-521, DOI:10.1007/BF02427963.

[16] Ewins, D.J. (2000). Modal Testing: Theory, Practice and Application. Research Studies Press, Baldock.

[17] PULSE (2006). Analyzers and Solutions, Release 11.2, Bruel\&Kjaer, Sound and Vibration Measurement A/S, Nærum.

[18] ME'scopeTM (2001). Version: 2.0.0.21. Vibrant Technology, Scotts Valley. 